\title{
Inhaled nitric oxide for pulmonary hypertension after repair of exomphalos
}

\author{
O I Miller, J W Gaynor, D J Macrae, R C Tasker
}

\begin{abstract}
Inhaled nitric oxide was used successfully to treat a newborn infant with severe pulmonary hypertension complicating repair of congenital exomphalos. The infant had failed conventional treatment and extracorporeal membrane oxygenation was unsuitable because of the risk of bleeding from the recent laparotomy. Extended treatment with inhaled nitric oxide appears safe and may offer an alternative to mechanical life support in severe cases of neonatal pulmonary hypertension. (Arch Dis Child 1993; 69: 518-520)
\end{abstract}

Surgery for congenital exomphalos entails primary closure of smaller defects or a staged procedure for larger defects. Postoperative care may be complicated by circulatory compromise due to venous obstruction or significant pulmonary embarrassment either from transmitted intra-abdominal pressure or from coexisting lung hypoplasia. Postoperative pulmonary hypertension is an uncommon complication. ${ }^{1}$

The treatment of neonatal pulmonary hypertension has undergone a dramatic change in recent years. Extracorporeal membrane oxygenation (ECMO) is being used as supportive treatment in selected centres and more latterly inhaled low dose nitric oxide has been reported to be a selective pulmonary vasodilator after

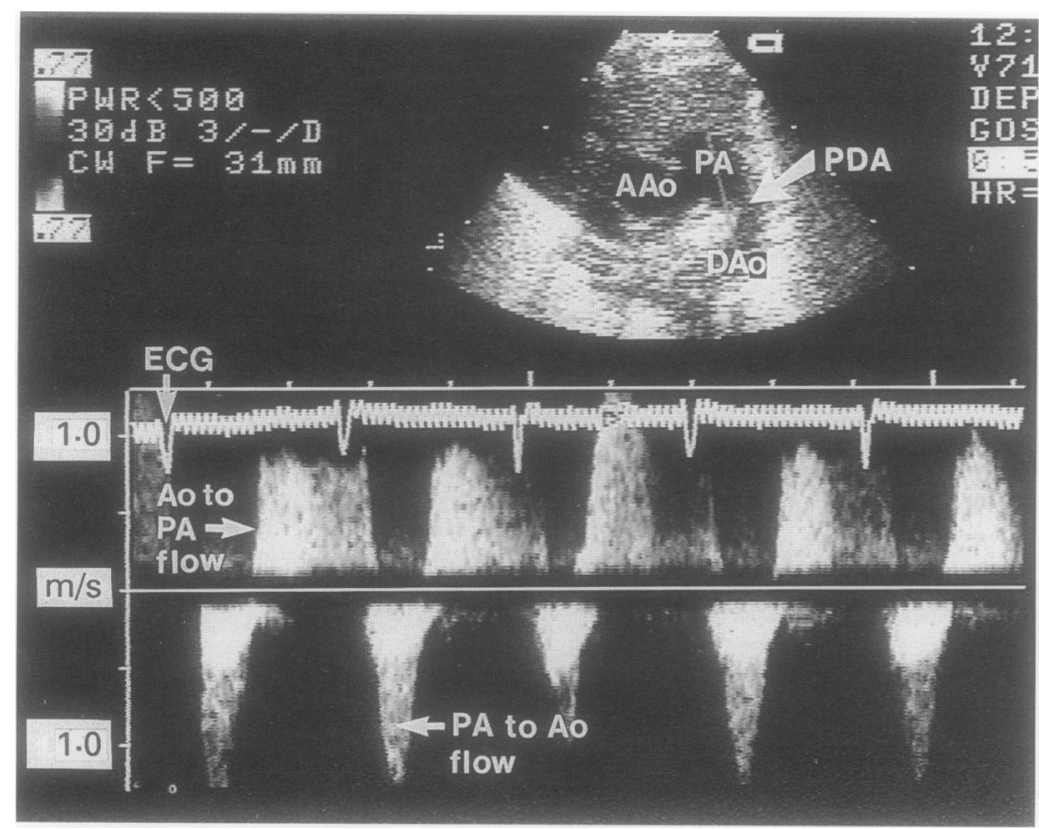

Figure 1 Two dimensional echocardiogram showing patent ductus arteriosus (PDA arrow) and Doppler flow signals showing flow which is right to left in systole and left to right in diastole. $A A o=$ ascending aorta, $P A=$ pulmonary artery, $D A o=$ descending aorta, and $E C G=$ electrocardiogram.

surgery for congenital heart disease ${ }^{2}$ as well as for persistent pulmonary hypertension in newborns. ${ }^{3} 4$

We report the use of inhaled low dose nitric oxide as a successful alternative to ECMO in a neonate with severe refractory pulmonary hypertension after primary repair of congenital exomphalos.

\section{Case report}

A boy weighing $3438 \mathrm{~g}$ was born by elective caesarean section for breech presentation at 39 weeks' gestation. Antenatal ultrasonography at 35 weeks' gestation had confirmed the breech presentation but had not recognised the exomphalos. At birth, the Apgar scores were 7 and 9 at 1 and 5 minutes respectively. A congenital exomphalos measuring $4.5 \mathrm{~cm}$ at its neck was evident but there was no evidence of associated chromosomal or congenital cardiac anomalies. The chest radiograph showed a bell shaped thorax suggestive of pulmonary hypoplasia. Initially the infant was nursed in supplemental oxygen (fractional inspired oxygen $\left.\left(\mathrm{FIO}_{2}\right) 0.35\right)$, commenced on intravenous antibiotics, and transferred to our institution for corrective surgery. An echocardiogram on day 1 was normal apart from a persistent ductus arteriosus. Laparotomy at 14 hours of age achieved primary reduction and closure with the abdomen under only minimal tension. The exomphalos had contained bowel, a small segment of liver, and the gallbladder.

Postoperatively there was progressive deterioration in gas exchange that could not be controlled by muscle relaxation, alkalotic hyperventilation, inotropic support (dobutamine), or a trial of exogenous surfactant (Exosurf, Wellcome). Repeat two dimensional echocardiography and Doppler revealed a blood flow pattern which was right to left across the ductus arteriosus during systole, consistent with suprasystemic pulmonary artery pressures (fig 1).

To grade the severity of pulmonary dysfunction and level of respiratory support required, the oxygenation index (OI) can be derived from the mean airway pressure $\left(\mathrm{P}_{\mathrm{aw}}\right), \mathrm{FIO}_{2}$, and the postductal arterial partial pressure of oxygen $\left(\mathrm{PaO}_{2}\right)$ where:

$$
\mathrm{OI}=\mathrm{P}_{\mathrm{aw}}\left(\mathrm{cm} \mathrm{H}_{2} \mathrm{O}\right) \times \mathrm{Fio}_{2} / \mathrm{PaO}_{2}(\mathrm{~mm} \mathrm{Hg}) \times 100 \%
$$

A single oxygenation index $>40$ or three successive values $>35$ while receiving maximal conventional treatment fulfil our institutional criteria for a therapeutic trial of ECMO. Our case had an oxygenation index exceeding 35 


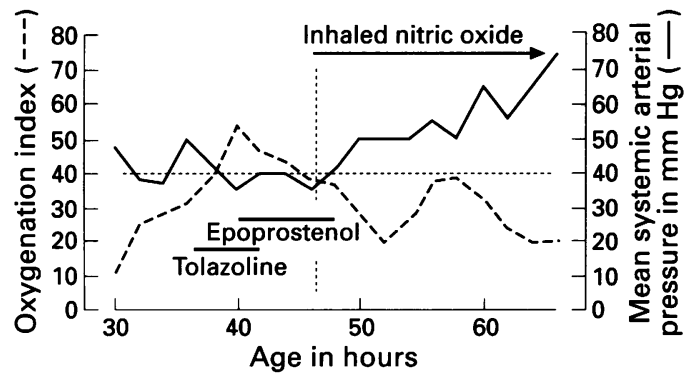

Figure 2 Oxygenation index and mean systemic arterial pressure plotted against age in hours. An index $>40$ is indicated by the horizontal dotted line. The vertical dotted line marks the start of exposure to inhaled nitric oxide.

for a total of seven hours with a maximum index of 54 (fig 2).

Tolazoline $(1 \mathrm{mg} / \mathrm{kg}$ bolus and continuous infusion $7 \mu \mathrm{g} / \mathrm{kg} / \mathrm{min}$ ) did not improve the oxygenation index. Continuous intravenous infusion of epoprostenol (prostacyclin) at 10 $\mu \mathrm{g} / \mathrm{kg} / \mathrm{min}$ led to a fall in the index (43 to 36 ) but was associated with a fall in the mean systemic arterial blood pressure from 50 to 35 $\mathrm{mm} \mathrm{Hg}$. Although ECMO was considered, it was deemed unsuitable because of the risk of bleeding from the recent laparotomy.

At 47 hours of age, in the face of severe systemic hypotension and persisting respiratory failure, inhaled nitric oxide was commenced in an attempt to achieve selective pulmonary vasodilatation. Nitric oxide (500 parts per million (ppm)) was titrated via a calibrated flowmeter into the inspiratory limb of a time cycled, pressure limited, continuous flow infant ventilator (Bearcub BP2001, Bear Medical Systems, California) to achieve an inhaled nitric oxide concentration of $15 \mathrm{ppm}$ in an $\mathrm{FIO}_{2}$ of $0 \cdot 85$. Monitoring of inspired nitric oxide and its toxic oxidative product nitrogen dioxide was performed by continuous chemiluminescent analysis (TEI 42, Thermo Electron). Although there was some improvement in the oxygenation index during the first two hours of combined inhaled nitric oxide and epoprostenol treatment, a greater fall in the index coincided with discontinuation of epoprostenol. Sustained improvement was evident over the next 30 hours during administration of inhaled nitric oxide at concentrations between 15-20 ppm. Subsequent reduction and weaning of inhaled nitric oxide was well tolerated with discontinuation of the nitric oxide treatment after a total of 71 hours. At no stage was the arterial methaemoglobin raised nor did the nitrogen dioxide concentration exceed 1 ppm.

Clinical and radiological improvement continued and by day 6 the infant was requiring only $50 \%$ supplemental oxygen yielding an oxygenation index less than 10. Successful extubation was achieved on day 11 of life.

\section{Discussion}

Potentially fatal persistent pulmonary hypertension of the newborn (PPHN) continues to be a major management problem in infants with severe hyaline membrane disease, meconium aspiration, perinatal asphyxia, or congenital diaphragmatic hernia. Lung hypoplasia associated with congenital exomphalos may contribute to PPHN in affected infants. Severe reactive pulmonary hypertension may also occur after repair of certain congenital heart lesions and conventional management may be only partially successful with the efficacy of intravenous vasodilators often limited by systemic hypotension. ${ }^{5}$ Furthermore, in the presence of patchy atelectasis, intravenously administered vasodilators may worsen intrapulmonary right to left shunting by vasodilating both ventilated and under ventilated areas. ${ }^{6}$

In the lung, endothelial production of nitric oxide is considered fundamental to constant active vasodilatation ${ }^{7}$ and endothelial dysfunction has been implicated in children with abnormal pulmonary haemodynamics. ${ }^{8}$ Inhaled nitric oxide should optimise ventilationperfusion matching by being selective for the pulmonary vessels immediately adjacent to ventilated alveoli. Systemic vasorelaxation is precluded by the inactivation of nitric oxide by avid binding to haemoglobin ${ }^{9}$ in the pulmonary capillaries and any resulting rise in methaemoglobin has not been clinically significant in recent reports, ${ }^{34}$ similar to our own experience.

Our case highlights the efficacy of inhaled low dose nitric oxide in improving oxygenation without compromising the systemic circulation when used during conventional ventilation. Concurrent use of intravenous vasodilators may prolong hypoxaemia and systemic hypotension with significant simultaneous improvement in both systemic blood pressure and oxygenation first occurring after administration of monotherapy with inhaled low dose nitric oxide.

\section{CONCLUSION}

Inhaled low dose nitric oxide appears to be a safe, efficacious, and selective pulmonary vasodilator when used clinically over an extended period. Furthermore, we believe that inhaled nitric oxide may be a useful treatment of neonatal pulmonary hypertension in cases where ECMO is unsuitable. However, it should be remembered that inhaled nitric oxide is still an experimental treatment currently lacking an optimum dose range, detailed clinical toxicities, and supportive clinical trials. Until these are available, it is imperative that each administration of inhaled nitric oxide be accompanied by continuous analysis of inspired nitric oxide and nitrogen dioxide, serial analysis of methaemoglobin, and critical review of the clinical course and all adverse effects.

We thank Mr E Kiely for permission to report this patient and Vanda Gooch for preparation of figure 1 (echocardiogram). Dr Miller is supported by the British Heart Foundation.

1 Lafferty PM, Emmerson AJ, Fleming PJ, Frank JD, Noblett HR. Anterior abdominal wall defects. Arch Dis Child 1989; 64: 1029-31.

2 Miller OI, James I, Elliott MJ. Intraoperative use of inhaled low dose nitric oxide. $\mathcal{f}$ Thorac Cardiovasc Surg 1993; 105: 550-1

3 Roberts JD, Polander DM, Lang P, Zapol WM. Inhaled nitric oxide in persistent pulmonary hypertension of the newborn. Lancet 1992; 340: 818-9. 
4 Kinsella JP, Neish SR, Shaffer E, Abman SH. Low-dose inhalational nitric oxide in persistent pulmonary hypertension of the newborn. Lancet 1992; 340: 819-20.

5 Hopkins RA, Bull C, Haworth SG, de Leval MR, Stark J. Pulmonary hypertensive crises following surgery for congenital heart defects in young children. Eur $\mathcal{f}$ Cardiothorac Surg 1991; 5: 628-34.

6 Rossaint R, Falke KJ, López F, Slama K, Pison U, Zapol WM. Inhaled nitric oxide for the adult respiratory distress syndrome. N Engl f Med 1993; 328: 399-405.
7 Moncada S, Radomski MW, Palmer RM. Endotheliumderived relaxing factor. Biochem Pharmacol 1988; 13: 2495-501.

8 Celermajer DS, Cullen S, Deanfield JE. Impairment of endothelial dependent pulmonary artery relaxation in children with congenital heart disease and abnormal pulmonary hemodynamics. Circulation 1993; 87: 440-6.

9 Ignarro LJ. Biological actions and properties of endotheliumderived nitric oxide formed and released from artery and vein. Circ Res 1989; 65: 1-21. 